\title{
EDUCAÇÃO INCLUSIVA EM UMA ESCOLA DO CAMPO DE TERESINA (PI): DA SALA REGULAR AO ATENDIMENTO EDUCACIONAL ESPECIALIZADO (AEE)
}

\section{Inclusive education in a school in the field of Teresina (PI): from the regular room to the Specialized Educational Service (AEE)}

\author{
Daiane dos Santos Gomes ${ }^{1}$ \\ Keyla Cristina da Silva Machado ${ }^{2}$
}

\begin{abstract}
RESUMO: A Educação do Campo e a Educação Especial, historicamente, veem sofrendo com negação de direito social. No Brasil, tem-se presenciado um grande movimento pela inclusão escolar, para que as pessoas com deficiência passem a ter cada vez mais seus direitos assegurados, e os alunos com Necessidades Educacionais Especiais (NEE) tenham acesso ao Atendimento Educacional Especializado (AEE). A partir desses aspetos, idealizou-se a realização desta estudo, que teve como objetivo analisar as práticas inclusivas utilizadas em salas regulares e de AEE com alunos de uma escola do campo, permitindo refletir quais as dificuldades que os profissionais da educação têm que lidar dentro do contexto da inclusão, em busca da garantia do direito à educação por indivíduos da Educação Especial. A pesquisa é de caráter qualitativo, tendo como instrumentais utilizados na coleta de dados, questionários aplicado aos professores. Verificou-se que a formação docente é muito importante e que as práticas inclusivas utilizadas na sala regular são de fundamental importância no processo de inclusão, pois permitem a socialização e o desenvolvimento dos educandos na sala do AEE. O acompanhamento dos alunos permite quebrar as barreiras no processo de ensino e de aprendizagem, permitindo que eles participem ativamente das aulas, assegurando que tenham a continuidade nos estudos, em todos os níveis de ensino.
\end{abstract}

Palavras-chaves: Educação Inclusiva. Educação Especial. Escola do campo. Necessidades Educacionais Especiais (NEE). Atendimento Educacional Especializado (AEE).

ABSTRACT: Rural Education and Special Education, historically, have suffered from the denial of social rights. In Brazil, there has been a great movement towards school inclusion, so that people with disabilities are increasingly guaranteed their rights, and students with Special Educational Needs (NEE) have access to Specialized Educational Assistance (AEE). Based on these aspects, this study was idealized, which aimed to analyze the inclusive practices used in regular and ESA classrooms with students from a rural school, allowing to reflect on the difficulties that education professionals have to deal with. the context of inclusion, in search of guaranteeing the right to education by individuals from Special Education. The research is of qualitative character, having as instruments used in the data collection, questionnaires applied to the teachers. It was found that teacher training is very important and that inclusive practices used in the regular classroom are of fundamental importance in the inclusion process, as they allow the socialization and development of students in the ESA room. The monitoring of students allows to break the barriers in the teaching and learning process, allowing them to participate actively in the classes, ensuring that they have continuity in their studies, at all levels of education.

\footnotetext{
${ }^{1}$ Discente do curso de Licenciatura em Educação do Campo pela Universidade Federal do Piauí (UFPI), Campus Ministro Petrônio Portella (CMPP), em Teresina (PI). E-mail: daiannesantos98@hotmail.com

${ }^{2}$ Doutoranda em Educação pela Universidade Federal do Piauí (UFPI). Professora do Curso de Licenciatura em Educação do Campo (LEdoC) da UFPI, Campus Ministro Petrônio Portella (CMPP), em Teresina (PI). E-mail: keylacrissmachado@ufpi.edu.br
} 
Keywords: Inclusive education. Special education. Countryside school. Special Educational Needs (NEE). Specialized Educational Service (AEE).

\section{CONSIDERAÇÕES INICIAIS}

No Brasil, tem-se presenciado um grande movimento pela inclusão escolar, para que as pessoas com deficiência passem a ter cada vez mais seus direitos assegurados, e os alunos com Necessidades Educacionais Especiais (NEE) tenham acesso ao Atendimento Educacional Especializado (AEE).

Moura (2016) afirma que a Educação Inclusiva ganhou destaque no contexto internacional com a Declaração Mundial de Educação para Todos, em Jomtien, Tailândia, na década de 1990; e com a Declaração de Salamanca, em 1994. Esses movimentos apontaram para a importância da democratização do acesso à escola, possibilitando o atendimento às necessidades educacionais de todos, buscando unir esforços da sala regular e AEE para atender as NEE dos alunos. Destacaram ainda, que no processo educacional tem-se uma perspectiva qualitativa para todos os educandos, porém, a limitação do tema faz com que os impasses se tornem maiores na busca da efetivação dos direitos à educação das pessoas com deficiências.

A inclusão tem por objetivo a melhoria do ensino e do espaço educacional, considerando que os componentes curriculares são variados e tornam-se cansativos aos alunos e professores, fazendo com que eles fiquem a mercê de um programa que pouco explora o potencial dos alunos, desconsiderando, muitas vezes, suas habilidades adquiridas. Esses fatores resultam em exclusão e fracasso, para aqueles que não atendem as expectativas da turma sala de aula regular. É importante ressaltar que a educação inclusiva não compreende somente pessoas com deficiências, mas a escola como um espaço de aprendizagem significativa para todos os discentes (POZZER, 2015).

Nesse sentido, a Educação do Campo considera que todos possuem direito ao conhecimento, independente das especificidades que apresentem, podendo assim, ser agentes transformadores da realidade, exercitando a prática do saber, pois, em sua maioria, são filhos e filhas de trabalhadores rurais, onde o acesso à educação é bastante precário.

Levando que consideração essa temática, pensou-se em realizar esta pesquisa, a partir das observações, experiências vivenciadas e reflexões realizadas durante as disciplinas de Estágio Supervisionado I e II do curso de Licenciatura em Educação do Campo (LEdoC)/Ciências da Natureza (UFPI), além da participação, da primeira autora, no Programa Mais Alfabetização, como professora auxiliar em uma escola municipal da comunidade Chapadinha Sul, onde teve contato 
com crianças especiais e que tinham algumas dificuldades de aprendizagem, além da carência e a falta de estudos sobre esse tema dentro das escolas do campo.

Como metodologia do estudo, desenvolveu-se uma pesquisa descritiva, de caráter qualitativo, em uma Escola Municipal de Ensino Fundamental em Teresina (PI), localizada na BR 316, zona rural. No primeiro momento, foi apresentada a proposta da pesquisa sobre a Educação Inclusiva para alunos do campo, para os professores das disciplinas regulares e para a docente que acompanha a sala do AEE, além da equipe de gestão da instituição, mostrando como seria a pesquisa e a importância de sua participação.

Os sujeitos, interlocutores da pesquisa, são constituídos de 01 (uma) professora do AEE e 02 (duas) docentes da sala regular, sendo uma de Ciências e outra de Geografia. Esses profissionais foram selecionados através dos seguintes critérios: disponibilidade e aceite para participar, ser professor efetivo da escola.

Nesse cenário, utilizou-se como instrumento de coleta de dados, questionários com perguntas abertas, realizados no mês de março de 2019, com perguntas diferenciadas para professores da sala regular e AEE. Dessa maneira, o questionário tornou-se fundamental na coleta de informações de forma para se chegar à realidade do problema da pesquisa.

Após todas as atividades realizadas, os dados dos questionários foram analisados, a partir da análise de conteúdo baseada em Bardin (2011), na tentativa de compreender os partícipes e o lócus da pesquisa. Também, no processo de análise, aqui apresentada, os sujeitos são referidos por nomes fictícios e genéricos, de modo a preservar suas identidades.

Diante disso, indagamos quais práticas inclusivas são desenvolvidas nas salas de aula regular e no AEE nas escolas do campo. A intenção é refletir de forma mais ampla acerca das dificuldades enfrentadas no processo de inclusão nas escolas do campo, bem como, as práticas inclusivas desenvolvidas para que esse processo de fato aconteça.

Para tanto, tem-se como objetivo geral, analisar as práticas inclusivas utilizadas nas salas regulares e AEE com alunos de escola do campo na comunidade referida. E, como objetivos específicos: caracterizar as práticas inclusivas utilizadas na sala regular e de AEE situadas em escola do campo; verificar como os professores da sala regular e os professores do AEE articulam seu trabalho no desenvolvimento de práticas inclusivas em escolas do campo, além de identificar as principais dificuldades enfrentadas pelos professores na inclusão dos alunos especiais nas escolas do campo. A pesquisa é de caráter qualitativo, tendo como instrumentais utilizados na coleta de dados, questionários, aplicado aos professores.

Mediante a situação em que se encontra a educação inclusiva no campo, cabe ampliar a discussão, direcionando o foco para o aperfeiçoamento e a melhoria na preparação dos 
profissionais envolvidos no processo de ensino, e com isso, tornar o ambiente escolar um lugar de acolhimento e de maior desenvolvimento, onde haja respeito diante das especificidades dos educandos.

Este texto seguirá descrevendo a educação inclusiva nas escolas do campo e do AEE; em seguida, serão expostos os achados da pesquisa, bem como, as análises dos dados produzidos; e, nas considerações finais, o que foi possível concluir a partir da pesquisa.

\section{DESENVOLVIMENTO}

\subsection{Educação inclusiva nas escolas do campo}

A Educação do Campo vai além de uma modalidade de ensino, deve ser entendida e discutida como uma política pública, na intenção de garantir os mesmos direitos educacionais garantidos à população camponesa. As leis que regulamentam a Educação no Campo são de suma importância e devem ser expostas e estudadas, pois levam ao contexto escolar camponês métodos e práticas educativas articulados com a cultura local, identidade e realidade da população do campo (RODRIGUES; BONFIM, 2016). Conforme a Lei de Diretrizes e Bases da Educação, LDB, 9.394/96, no Art. 28:

Art. 28. Na oferta de educação básica para a população rural, os sistemas de ensino promoverão as adaptações necessárias à sua adequação às peculiaridades da vida rural e de cada região, especialmente: I - conteúdos curriculares e metodologias apropriadas às reais necessidades e interesses dos alunos da zona rural; II - organização escolar própria, incluindo adequação do calendário escolar às fases do ciclo agrícola e às condições climáticas; III - adequação à natureza do trabalho na zona rural. (BRASIL,1996, p. 16)

Nesse contexto, mesmo com a lei que assegura a Educação do Campo e no campo, o que se vê é que ainda há grande dificuldade em manter as escolas de portas abertas, seja pela falta de estrutura, de manutenção e, principalmente, de investimentos. Nesse cenário, a educação inclusiva merece igualmente destaque e importância, devendo ser capaz de oferecer a todos os alunos, inclusive aos alunos com NEE, condições para o desenvolvimento acadêmico, respeitando suas possibilidades de forma que eles, igualmente, tenham condições de acesso e oportunidades no mercado de trabalho e na vida (PALMAS; CARNEIRO, 2018).

A Educação do Campo e a Educação Especial historicamente possuem aspectos comuns, quanto a negação de direitos, e, no que diz respeito a segunda, a Resolução n²/2008 referente a política pública de atendimento da Educação Básica do Campo, afirma que: 
$\int 5^{\circ}$ Os sistemas de ensino adotarão providências para que as crianças e os jovens portadores de necessidades especiais (sic), objeto da modalidade de Educação Especial, residentes no campo, também tenham acesso à Educação Básica, preferentemente em escolas comuns da rede de ensino regular. (BRASIL, 2008 a, p. 01)

Desse modo, concorda-se com Palma; Carneiro (2018) ao destacarem que os indivíduos com NEE, que residem no campo são duplamente vulneráveis, pois têm que lidar com as dificuldades pessoais e do local em que vivem. Ao longo dos anos, houve avanço nesse contexto, porém, as escolas do campo ainda estão pouco preparadas para atender o público-alvo da Educação Especial.

\subsection{Atendimento Educacional Especializado (AEE)}

A partir da década de 1990, tem-se presenciado um grande movimento pela inclusão escolar, as pessoas com deficiência passaram a ter seus direitos assegurados e, desde então, os alunos NEE tiveram acesso ao AEE (MANTOAN, 2011).

Ainda na fala de Mantoan (2011), ao longo dos anos, as pessoas com deficiências tiveram de quebrar bastantes paradigmas, além de vivenciarem situações de exclusão pela sociedade, principalmente, no âmbito escolar, por serem especificados como "diferentes" e com incapacidade de acompanhar as outras pessoas, ditas como neurotípicas, termos usados para referir-se às crianças que não apresentam deficiência. No século passado, iniciou-se o processo de desenvolvimento da Educação Especial no Brasil, ainda por iniciativas de caráter privado e foi necessário mais de um século para que estas fizessem parte das políticas públicas de educação, tornando a Educação Especial uma das modalidades de ensino componentes do sistema educacional brasileiro.

A estruturação da Educação Especial no Brasil seguiu, por inúmeras vezes, modelos que priorizam o assistencialismo, embasado numa segmentação das deficiências e, por uma visão segregativa, fazendo com que a vida social e a formação de pessoas com deficiência ocorressem em um plano à parte. Com a criação das campanhas que atendiam especificamente cada deficiência, em 1957, a Educação Especial foi assumida pelo poder público, primeiramente com campanhas para a educação do surdo e depois outras campanhas similares foram criadas para atender outras deficiências (MANTOAN, 2011).

Desse modo, surge como uma forma de esperança para as pessoas que eram excluídas pela sociedade, abrindo a possibilidade de também terem acesso à Educação Básica e de poderem 
mostrar suas potencialidades, pois as mesmas eram descriminadas por não acompanharem um modelo de ensino excludente.

Incluir pessoas com deficiências é visto ainda, como um sonho a ser concretizado nas escolas, já que elas ainda estão muito abaixo da realidade das crianças inclusas, principalmente nas escolas do campo, sobretudo, pela falta de infraestrutura adequada. Sendo assim:

A educação especial, a partir das políticas instituídas da Educação Inclusiva, tem o papel de combater a discriminação do olhar de incapacidade das pessoas com deficiência e a Educação do Campo busca combater a discriminação no meio rural como lugar de atraso, no qual não há desenvolvimento e tecnologia, ressaltando que estas duas áreas sofrem pela produção social do preconceito. (PALMAS, 2016, p. 21-22)

É preciso ampliar as discussões para que as crianças e adolescentes que residem e estudam em escolas do campo não sofram duplamente pela indiferença negativa, desenvolvida pela falta de políticas públicas, que assegurem seus direitos.

As escolas inclusivas devem atender as especificidades dos sujeitos que moram no campo e as estratégias desse atendimento não podem ser únicas, padronizadas e normalizadas. Então, as escolas situadas em perímetro rural necessitam está adequada à realidade sociocultural em que está inserida, onde seja capaz de proporcionar melhores condições para aprendizagem dos seus educandos (PALMAS, 2016).

A luta pela inclusão escolar vem ganhando notoriedade na sociedade e já conseguiu muitos pontos positivos. A Constituição Brasileira (BRASIL, 1988) mostra que o estado tem o dever de oferecer igualdade, acesso à educação e também ao:

II - atendimento educacional especializado aos portadores de deficiências, preferencialmente; $\mathrm{V}$ - acesso aos níveis mais elevados do ensino, da pesquisa e da criação artísticas, segundo a capacidade de cada um. (BRASIL, 1988, p. 118)

Dessa forma, é necessário que os direitos sejam garantidos, não somente na teoria, mas na prática, pois o que se vê é uma realidade bem diferente do que deve ser assegurado pelo estado. Portanto, o AEE tem como função:

Elaborar e organizar recursos pedagógicos e de acessibilidade que eliminem as barreiras para a plena participação dos alunos, considerando suas necessidades específicas. As atividades desenvolvidas no atendimento educacional especializado diferenciam-se daquelas realizadas na sala de aula comum, não sendo substitutivas à escolarização. Esse atendimento complementa e/ou suplementa a formação dos alunos com vistas à autonomia e independência na escola e fora dela. (BRASIL, 2008b, p. 10) 
Nesse contexto, o Decreto 6.571, de 17 de setembro de 2008 (BRASIL, 2008c), apresenta os objetivos do AEE:

Art. $2^{\circ}$ São objetivos do atendimento educacional Especializado: I - prover condições de acesso, participação e aprendizagem no ensino regular; II - garantir a transversalidade da educação especial no ensino regular; III - fomentar o desenvolvimento dos recursos didáticos e pedagógicos que eliminem as barreiras no processo de ensino e aprendizagem; IV - assegurar as condições para a continuidade de estudos nos demais níveis de ensino. (BRASIL, 2008c, p. 01)

Então, esse atendimento não é uma forma de substituição do ensino regular, mas um auxílio e um instrumento para a inclusão dos alunos na sala de aula comum, além de proporcionar uma maior interatividade, dentro e fora do contexto escolar.

O AEE mostra a necessidade de mudança no sistema educacional, com objetivo de criar condições para que haja a participação de todos os alunos, pois leva os professores a repensarem suas práticas de ensino e integra a proposta pedagógica da escola regular. Dessa forma, o AEE busca contemplar o aluno com deficiência na sala de aula, que tem o acompanhamento do professor especialista, fazendo com que ele tenha acesso ao conhecimento dentro das suas possibilidades e a presença física dentro da sala regular (PALMAS, 2016).

Existe, portanto, a necessidade de políticas públicas que ampliem os investimentos em infraestrutura e formação de professores, para que seja alcançado o objetivo de fornecer recursos e orientações para o ensino adequado, de acordo com o tipo de deficiência dos discentes.

\section{PRÁTICAS INCLUSIVAS EM ESCOLAS DO CAMPO}

Esta sessão, trata dos resultados obtidos através dos questionários, relacionando as respostas dos professores de ensino regular e do professor do AEE e referenciando o conteúdo com obras de autores estudiosos do assunto; além de comentários dos autores da presente pesquisa.

\subsection{Práticas inclusivas na sala regular em escolas do campo}

As práticas inclusivas desenvolvidas na sala de aula ainda são insuficientes e os professores da sala regular têm consciência da importância da educação inclusiva na Educação Especial no processo de desenvolvimento dos alunos, como é possível observar nas seguintes falas:

A educação inclusiva é importante para a socialização de alunos com necessidades especiais. (FORÇA, 2019) 
É uma educação que traz união, que se adapta as diferenças e dificuldades do aluno, que explora e intensifica no seu processo cognitivo, social e emocional. (GENTILEZA, 2019)

Dessa forma, pode-se perceber que a educação inclusiva permite a interação dos alunos, conforme disse Força; e ainda se adéqua as diferenças e as dificuldades enfrentadas pelos mesmos, fazendo com que haja maior desenvolvimento integral, como declara Gentileza.

Sendo assim, a Política Nacional de Educação Especial na perspectiva da Educação Inclusiva (BRASIL, 2008b), enfatiza a importância dos serviços de estimulação precoce, com o objetivo de melhorar o processo de aprendizagem e desenvolvimento da criança, concomitantemente aos serviços de saúde e assistência social; além do mais, no AEE, as atividades desenvolvidas promovem autonomia e independência no âmbito escolar e fora dele. Percebe-se que a educação inclusiva estimula a convivência com as diferenças, o que favorece as relações interpessoais e promove o respeito e a valorização do aluno.

Os professores reconhecem a importância do ensino inclusivo, porém, no que se refere a buscar metodologias de inclusão nas aulas e a utilização das mesmas, relataram:

\author{
Raramente. (FORÇA, 2019) \\ Sinceramente, ainda não. Reconheço que preciso e já senti muita necessidade por não ajudar o \\ aluno no seu aprendizado. (GENTILEZA, 2019)
}

Dessa maneira, segundo a fala de Força, ela raramente busca novas formas metodológicas em suas aulas e Gentileza afirma que não há essa busca de metodologias diferenciadas em suas aulas, porém, reconhece que necessita buscá-las para auxiliar no processo de aprendizagem dos seus alunos, ao mesmo tempo, em que ressalta a falta de conhecimento dos educadores.

Sobre isso, Oliveira (2018) salienta essa necessidade e importância, pois afirma que as metodologias inclusivas permitem rever concepções, possibilitando a mudança de relações e ao estabelecimento de uma cultura de inclusão, pois esta rompe com padrões normativos e práticas pedagógicas homogeneizadoras.

Assim sendo, é evidente que haja uma mudança não somente em relação à busca de novas metodologias, mas também, no processo de formação dos profissionais de educação, pois eles precisam conhecer as especificidades de seus alunos. Nesse contexto, consta na Declaração de Salamanca (1994):

É preciso repensar a formação de professores especializados, a fim de que estes sejam capazes de trabalhar em diferentes situações e possam assumir um papelchave nos programas de necessidades educativas especiais. Deve ser adoptada uma formação inicial não categorizada, abarcando todos os tipos de deficiência, 
antes de se enveredar por uma formação especializada numa ou em mais áreas relativas a deficiências especificas. (DECLARAÇÃO DE SALAMANCA, 1994, p. 28)

Diante disso, a Declaração evidencia a relevância da igualdade, no que se refere à qualidade na educação em todos os aspectos e para os diferentes grupos, assim como promover a capacitação e o conhecimento aos professores para que estes possam assumir esse papel tão importante nessa transformação tão significativa da educação.

De acordo com percepção dos docentes, a falta de preparação para a inclusão no seu trabalho, causa alguns impactos, como demonstra as alternativas escolhidas pelos participantes abaixo:

Causa uma sensibilização em relação as pessoas com deficiência. Amplia o olhar sobre a diversidade, inclusive no ambiente escolar. Causa angústia, não poder trabalhar de forma adequada com este aluno. Rompe paradigmas em relação as pessoas com deficiência. (FORÇA,2019)

Causa angústia, não poder trabalhar de forma adequada com este aluno. (GENTILEZA, 2019)

Causa angústia, não poder trabalhar de forma adequada com este aluno. Causa uma recompensa pessoal, uma vez. que, reafirma o meu papel de educador. Causa uma sensibilização em relação as pessoas com deficiência. Amplia o olhar sobre a diversidade, inclusive no ambiente escolar. Rompe paradigmas em relação as pessoas com deficiência. (CORAGEM, 2019)

Nesse aspecto, observa-se a impotência desses profissionais diante dos desafios a eles expostos, no que se refere ao trabalho educacional de pessoas com deficiência, mostrando assim, que há um longo caminho ser percorrido.

O professor precisa ter um olhar atento para observar seus alunos. Desse modo, com relação à percepção do professor se na sua sala existem alunos que necessitam de AEE e como é a aceitação do aluno com NEE por parte dos demais, evidenciam:

Sim. Mas a família se recusa a aceitar. (FORÇA, 2019)

Sim, por que transparece em sua contextualização das atividades de classe e casa, no comportamento. (GENTILEZA, 2019)

Excelente não há atitudes de preconceito. A uma socialização entre eles. (FORÇA, 2019)

Ainda temos a não aceitação, como a questão de brincadeiras, falta de entrosamento e bulling. (GENTILEZA, 2019)

É de grande importância as crianças deficientes estarem interagindo com os ditos normais, é na troca de experiência que vão evoluindo nos aspectos sócio afetivo e cognitivo. (CORAGEM, 2019) 
Dessa maneira, é possível verificar que, tanto Força como Gentileza, estão atentas as dificuldades enfrentadas por alguns alunos e de que os mesmos necessitam de atendimento especializado. Força ainda relata, na sua fala, a falta de aceitação por parte da família. Diante disso, elas também relataram a aceitação do aluno especial pelos demais, quando Força diz que há uma boa relação entre eles, porém, Gentileza afirma que ainda há dificuldades na aceitação dos alunos especiais, pois os demais ainda têm atitudes de preconceito e Coragem, em sua fala, evidencia a importância da aceitação dos alunos especiais pelos demais, que promove uma evolução tanto no aspecto sócio afetivo como no cognitivo.

\subsection{Dificuldades relatadas pelos professores}

$\mathrm{Na}$ busca por uma educação inclusiva ainda há bastante dificuldades, no que se refere ao receber um aluno com NEE em sua sala de aula, como é possível observar nas falas abaixo:

A falta de preparo para trabalhar com alunos. (FORÇA, 2019)
De poder ensinar com a forma adequada, para isso deveria ter mais formação e cursos. (GENTILEZA, 2019)

Diante das falas apresentadas é notório ver que, tanto Força quanto Gentileza, encontram dificuldades ao receber esses alunos. Gentileza ainda salienta que deveria haver mais formações ou cursos para auxiliar e ajudar nessas barreiras que ainda existe no processo de inclusão.

A respeito disso, Marcoccia (2012) comenta que a problemática do processo educacional inclusivo em escolas públicas do campo é notória, pois alunos e professores convivem com a mesma realidade, enfrentando a deficiência nos processos de formação continuada e a carência de recursos físicos e materiais pedagógicos. A autora salienta ainda, que a garantia de formação continuada sólida aos professores, depende dos recursos financeiros que darão a estes condições para permanecer nas escolas públicas do campo.

No que se refere ao uso de uma linguagem adequada para compreensão do conteúdo por todos os alunos, os professores relataram:

Não. (FORÇA, 2019)

Utilizo de forma não tão adequada, por que uso uma linguagem igual para todos. (GENTILEZA, 2019) 
Segundo os relatos dos docentes, o que se percebe é a falta de uma linguagem adequada para a compreensão de todos os educandos, fazendo com que alguns alunos não avancem em relação aos conteúdos.

Quando se fala de inclusão, não é apenas o fato de se colocar um aluno especial dentro da sala de aula, mais permitir que ele possa socializar com os demais alunos e que desenvolva suas inúmeras habilidades. Mas, para que isso aconteça, os professores necessitam ter um olhar mais atento em relação aos alunos que possuem NEE, para que os mesmos sejam incluídos efetivamente em suas salas de aulas. Dessa forma, adaptar as avaliações e as atividades é uma maneira de favorecer a participação e a socialização entre todos os alunos, devendo o professor esclarecer as razões do porquê das adaptações aos mesmos, como se vê nas seguintes falas:

\section{Somente avaliação. (FORÇA, 2019)}

Não. Deixamos as avaliações para a professora do AEE explicar, mas só as vežes. (GENTILEZA, 2019)

Sim. (FORÇA, 2019)

Sim, mas só no acompanhamento do AEE. Às vezes volto a explicação e pergunto e tiro as dúvidas. (GENTILEZA, 2019)

Sim. (FORÇA, 2019)

Sim. Peço que os colegas ajudem nas atividades e na aceitação das diferenças e o respeito. (GENTILEZA, 2019)

Desse modo, vemos que Força adapta apenas as avaliações; e Gentileza não faz adaptação, nem de atividades e nem de avaliações, cabendo ao professor do AEE, algumas vezes, fazer a explicação das avaliações para os alunos com NEE. Força, ainda diz que favorece a participação em atividades em grupos e explica os motivos das adaptações aos demais alunos. Gentileza diz que favorece a participação em atividades em grupo, mas se contradiz na sua fala em relação a justificativa das adaptações, tendo em vista que não faz nenhuma adaptação em suas atividades ou avaliações. No tocante a esses aspectos, Silva (2008, p. 46) comenta:

[...] é fato que solucionar criativamente os problemas enfrentados na prática pedagógica e adotar atitudes inclusivas no trato com a diversidade são requisitos essenciais para a construção de uma educação de qualidade que atenda a todas as pessoas, sem qualquer tipo de distinção. 
Dessa maneira, é essencial buscar incluir os alunos no ambiente em que estão inseridos e uma forma é adaptar atividades e avaliações, sendo essas práticas pedagógicas importantes no melhoramento da educação, fazendo assim, com que estes alunos de fato se sintam acolhidos.

Para que haja um melhor desenvolvimento no processo de inclusão é importante que os professores da sala regular troquem informações frequentemente com o professor do AEE, acerca de uma melhor forma de se trabalhar com a inclusão de seus alunos, como vemos nas falas dos professores:

\author{
Às vezes sobre atividades e formas de avaliação. (FORÇA, 2019) \\ Sempre a professora do AEE é solicitada tanto por mim e outros professores, na forma de \\ buscar melhor atender. (GENTILEZA, 2019)
}

Diante das seguintes falas, percebe-se que, Força e Gentileza trocam informações com o professor do AEE sobre atividades e avaliações. Gentileza ainda diz que a troca de informação é uma maneira de melhorar o atendimento com os seus alunos. Segundo Mendes (2009, p. 31):

\begin{abstract}
No tocante às metas da inclusão escolar, constatamos que especialistas professores de educação especial e da educação comum, estão todos aprendendo a trabalhar juntos para assegurar que todos os estudantes alcancem melhores desempenhos, e neste contexto, colaboração tem se tornado uma necessidade. A colaboração tem sido considerada chave para atender as complexas metas escolares, e para construir uma comunidade que responda às muitas demandas impostas aos sistemas de educação contemporâneos.
\end{abstract}

Portanto, a interação entres professores é essencial para o desenvolvimento de uma educação de qualidade para os alunos especiais, pois promove o crescimento intelectual e social.

\title{
3.3 Atendimento Educacional Especializado (AEE)
}

O AEE recebe vários tipos de deficiência e cada aluno possui suas especificidades. Sendo assim, o professor tem que buscar atender a cada uma, como revela a professora do AEE em relação a sua sala de aula:

--Deficiência Intelectual (D.I), Baixa Visão, Deficiência Física (D.F), Surdez, Transtornos globais do Desenvolvimento (TEA) e Deficiência Múltiplas.

--Sim. É elaborada um plano de intervenção para cada aluno. Cada aluno é um caso de estudo que deve ser estudado com base na problemática vivenciada pelo mesmo. (CORAGEM, 2019) 
Desse modo, é possível observar na fala de Coragem que sua sala de AEE recebe vários tipos de deficiência e que a mesma elabora atividades de intervenção, com base nas dificuldades enfrentadas por cada aluno. Nesse contexto, a Resolução no 04/2009 no Art. 13, aponta para o papel do professor especialista:

I - identificar, elaborar, produzir e organizar serviços, recursos pedagógicos, de acessibilidade e estratégias considerando as necessidades específicas dos alunos público-alvo da educação especial; II - elaborar e executar plano de Atendimento Educacional Especializado, avaliando a funcionalidade e a aplicabilidade dos recursos pedagógicos e de acessibilidade. (BRASIL, 2009, p. 03)

Diante disso, vemos a importância da preparação desses docentes para lidar com as diferentes necessidades de seus alunos, visto que cada aluno apresenta um desafio a ser enfrentado.

O professor do AEE enfrenta grandes dificuldades ao receber alunos com NEE, sendo essas dificuldades maiores ainda em escolas do campo, como podemos perceber na fala que segue:

Muitos professores tem receio de receber alunos deficientes por conta de nossas escolas serem
bastante seletistas. Sim por conta dos alunos serem transportados e o AEE funcionar no contra
turno, muitos pais não disponibilizam de tempo, fica bastante corrido por conta da distância.
Espaço físico não apropriado e a não aceitação da família e alguns professores;
Independentemente de escola cada aluno é um ser único, o professor deve ter a sensibilidade de
detectar e tentar somar as dificuldades de cada aluno respeitando suas limitações, mas ao mesmo
tempo seu potencial. No caso da minha escola um dos problemas que enfrento é o não acesso à
internet, também nossos alunos são transportados, moram bastante distante e fica difícil retornar
no contra turno. (CORAGEM, 2019)

Conforme a fala de Coragem, é possível perceber que há falta de aceitação inclusiva, até por parte de alguns professores. Além da falta de estrutura da própria escola. A Resolução do Conselho Nacional de Educação (CNE), nº 04/2009, no Art. 10, salienta que:

Art. 10. O projeto pedagógico da escola de ensino regular deve institucionalizar a oferta do AEE prevendo na sua organização: I - sala de recursos multifuncionais: espaço físico, mobiliário, materiais didáticos, recursos pedagógicos e de acessibilidade e equipamentos específicos; II - matrícula no AEE de alunos matriculados no ensino regular da própria escola ou de outra escola; III - cronograma de atendimento aos alunos; IV - plano do AEE: identificação das necessidades educacionais específicas dos alunos, definição dos recursos necessários e das atividades a serem desenvolvidas; $\mathrm{V}$ - professores para o exercício da docência do AEE; VI - outros profissionais da educação: tradutor e intérprete de Língua Brasileira de Sinais, guia-intérprete e outros que atuem no apoio, principalmente às atividades de alimentação, higiene e locomoção; VII redes de apoio no âmbito da atuação profissional, da formação, do desenvolvimento da pesquisa, do acesso a recursos, serviços e equipamentos, entre outros que maximizem o AEE. (BRASIL, 2009, p. 02) 
Portanto, a escola possui um papel fundamental, no que se refere ao oferecimento de uma estrutura adequada para que o AEE seja feito da melhor forma possível.

Dessa maneira, a interação entre o professor da sala do AEE e professores da sala regular, bem como, a troca de informações e a elaboração de atividades, também se torna um fator necessário para o melhor aprimoramento do ensino. As falas a seguir contextualizam essa relação:

Não. O AEE não se trata de um reforco escolar e sim o professor de AEE planeja atividades objetivando a eliminação das barreiras que dificulta a aprendizagem desse aluno na sala regular; Sim. É necessário, não só das avaliações como planejamentos por que alguns alunos necessitam das atividades de sala de aula ser adaptadas. Também acompanho atividades do aluno surdo (não tem interprete);

Frequentemente, porque é necessário faz̧er adaptação para alguns alunos com deficiência intelectual, também socializo a cada bimestre o relatório de avaliação dos alunos do AEE, mencionando os avanços e retrocesso apresentados por cada um. (CORAGEM, 2019)

Nos relatos acima, Coragem expõe a maneira como ocorre a interação com os demais professores, exemplificando as ações tomadas mediante o planejamento educacional e os processos pedagógicos. Diante disso, Bedaque (2015) em seu livro sobre o AEE, relata a importância da ação do professor especializado, juntamente com o professor e demais profissionais que assistem os alunos da classe regular. Essa ação integrada objetiva contribuir com um maior desempenho dos estudantes do ensino especializado.

\section{CONSIDERAÇÕES FINAIS}

Neste estudo, discutimos que o processo de inclusão nas escolas do campo ainda tem um longo caminho a ser percorrido, mostrando que é necessário um olhar mais atento das políticas governamentais, a fim de atender às necessidades econômicas, culturais, sociais e educacionais.

No que se refere aos objetivos, pode-se caracterizar as práticas inclusivas utilizadas na sala regular como sendo de fundamental importância no processo de inclusão, pois permite a socialização e o desenvolvimento, o qual não é somente educacional, mas sim, em todas as áreas da vida do educando e, nas salas do AEE, o acompanhamento desses alunos permite quebrar as barreiras no processo de ensino e aprendizagem, para que eles participem ativamente das aulas, assegurando para que tenham continuidade dos estudos em todos os níveis de ensino.

Os dados mostraram que os professores da sala regular e os professores do AEE articulam seu trabalho no desenvolvimento de práticas inclusivas em escolas do campo, pois o AEE não se trata de um reforço escolar, mas sim, de um complemento de interação com a sala regular, visando, de fato, um ensino inclusivo e de qualidade. 
Quanto às dificuldades enfrentadas pelos professores na inclusão dos alunos especiais nas escolas do campo, percebeu-se que os mesmos não se sentem seguros, principalmente, devido à falta de uma formação adequada, e de uma melhor articulação entre outros docentes e da gestão escolar, além da falta de assistência, matérias pedagógicos e de uma estrutura que, de fato, permita se trabalhar uma educação inclusiva de qualidade.

O olhar atento para os alunos atendidos pelo AEE nos mostra que eles necessitam de atenção especializada para que se desenvolvam em todas as áreas, seja no âmbito familiar, social e escolar. Isso só será possível se houver uma melhor articulação das políticas públicas, para melhorar o AEE nas escolas do campo.

Para que a educação inclusiva de fato aconteça é necessário que não somente a responsabilidade seja do professor do AEE, mas que haja uma interação, cooperação dos demais professores da sala regular, diretores e de todos os profissionais que fazem parte do contexto escolar dos alunos, bem como, a participação da família, que, de forma direta contribui para o desenvolvimento dos alunos.

\section{REFERÊNCIAS}

BARDIN, Laurence. Análise de Conteúdo. Lisboa: Edições 70, 2011.

BRASIL. Constituição da República Federativa do Brasil. Brasília: Imprensa Oficial, 1988.

BRASIL. Lei n. 9.394, de 20 de dezembro de 1996. Lei de Diretrizes e Bases da Educação Nacional. Estabelece as Diretrizes e Bases da Educação Nacional. Diário Oficial da União, Brasília, DF, 24 dez. 1996. Disponível em: < http://portal.mec.gov.br/seed/arquivos/pdf/tvescola/leis/lein9394.pdf >. Acesso em: 27 out. 2019.

BRASIL. Declaração de Salamanca: Sobre princípios, políticas e práticas na área das necessidades educativas especiais. Salamanca- Espanha, 1994.

BRASIL. Ministério da Educação. Conselho Nacional de Educação. Câmara de Educação Básica. Resolução $\mathbf{n}^{\circ}$ 2, de $\mathbf{2 8}$ de abril de 2008. Estabelece diretrizes complementares, normas e princípios para o desenvolvimento de políticas públicas de atendimento da Educação Básica do Campo, 2008a. Disponível em: < http://www.mec.gov.br >. Acesso em: 11 out. 2019.

BRASIL. Ministério da Educação. Secretaria de Educação Especial. Política Nacional de Educação Especial na Perspectiva da Educação Inclusiva. Brasília: MEC; SEESP, 2008b.

BRASIL. Ministério da Educação. Decreto 6.571, de 17 de setembro de 2008. Dispõe sobre o Atendimento Educacional Especializado. 2008c. Disponível em: < http://ww.mec.gov.br >. Acesso em: 25 dez. 2018. 
BRASIL. Conselho Nacional de Educação. Câmara da Educação Básica. Resolução no 4, de 2 de outubro de 2009. Institui Diretrizes Operacionais para o Atendimento Educacional Especializado na Educação Básica, modalidade Educação Especial. Brasília: CNE; CEB, 2009.

BEDAQUE, S. A. P. Atendimento Educacional Especializado. Mossoró: EDUFERSA, 2015.

MANTOAN, T. E. M. A Educação Especial no Brasil: da exclusão à inclusão escolar. LEPED/ Unicamp. Campinas, [s.v], [s.n], p. 2-4, 2011.

MARCOCCIA, P. C. P. Educação Especial nas escolas públicas do campo: desafios à formação continuada. In: XVI Encontro Nacional de Didática e Práticas de Ensino (ENDIPE), Anais... n ${ }^{\circ}$ XVI, Campinas, p. 19-22, 2012.

MENDES, Enicéia Gonçalves. A formação do professor e a Política Nacional de Educação Especial. In: Seminário Nacional de Pesquisa em Educação Especial: formação de professores em foco, Anais... 5. São Paulo, 2009.

MOURA, A. C. S. Politicas de Educação Inclusiva no Brasil: Uma análise da educação escolar para as pessoas com deficiências. In: IV seminário internacional inclusão em educação Universidade e participação. Anais... Rio de Janeiro, 2016.

OLIVEIRA, Anna Augusta Sampaio de. Préfacio. In: PAPIM, Angelo Antonio Puzipe; ARAUJO, Mariane Andreuzzi de; PAIXÃO, Kátia de Graça Moura; SILVA, Glacielma de Fátima (Orgs.). Inclusão Escolar: perspectivas e práticas pedagógicas contemporâneas. Porto Alegre: Editora Fi, 2018. p. 09-12.

ORGANIZAÇÃO DAS NAÇÕES UNIDAS PARA A EDUCAÇÃO, A CIÊNCIA E A CULTURA. Declaração originada da Conferência Mundial sobre Educação para Todos. Jomtien, Tailândia: UNESCO; UNICEF; PNUD e Banco Mundial, 1990.

PALMAS, D. T; CARNEIRO, R. U. C. Sala de recursos multifuncional em escolas do campo: direito assegurado? Interfaces da Educação, Paranaíba, v. 9, n. 27. p. 518-548, 2018.

PALMAS, D. T. Escolas do Campo e Atendimento Educacional Especializado em Sala de Recursos Multifuncional. 2016. 140 f. Dissertação (Mestrado em Educação) - Faculdades de Ciências e Letras. Universidade Estadual Paulista, Araraquara, 2016.

POZZER, A. A inclusão de alunos surdos em escolas regulares e os desafios para a formação de professores. 2015. 58 f. Dissertação (Mestrado em Educação) - Departamento de Ciências Humanas. Universidade Regional Integrada do alto Uruguai e das Missões, Frederico Westphalen, 2015.

RODRIGUES, H. C. C; BONFIM, H. C. C. A. Educação do Campo e seus aspectos legais. In: Congresso Nacional de Educação - EDUCERE: Formação de professores: contextos, sentidos e práticas, Anais... n XIII, 2016, Paraná: SIPD-Cátedra UNESCO, p. 1378-1379, 2016.

SILVA, L. G. dos S. Representações de professores e suas implicações para o sucesso escolar de um aluno cego. In: ONOFRE, Eduardo Gomes; SOUZA, Maria Lindaci Gomes de (Orgs.). Tecendo os fios da inclusão: caminhos do saber e do saber fazer. João Pessoa: Editora Universitária da UFPB, 2008. 